\title{
Haematocrit Value in Preeclampsia
}

\author{
SANKAR KUMAR BASAK ${ }^{1}$, KOHINOOR BEGUM ${ }^{2}$, MALIHA RASHID ${ }^{3}$, \\ NAHID YASMIN ${ }^{4}$, HASINABEGUM ${ }^{5}$
}

\begin{abstract}
:
Objective(s): To assess the association between the haematocrit value and severity of preeclampsia.

Materials \& Methods: This cross sectional study was conducted in the department of Obstetrics \& Gynaecology of Dhaka Medical College Hospital, Dhaka during the period of January 2012 to December 2013. Total of 100 patients were studied and they were divided into two groups - group-A and group-B. Fifty preeclamptic patients were included in the group- $A$ and 50 normal pregnant women were included in the group- $B$.

Results: Majority of preeclamptic women (68\%) and normal pregnant women (76\%) were in the age group of 20-30 years with the mean ages of group- $A$ and group- $B$ subjects were $26.50 \pm 5.71$ and $26.26 \pm 4.91$ years respectively. Eighty six percent of group $-A$ and $70 \%$ of group- $B$ women were of lower socioeconomic status. Majority of the study subjects (74\% of group-A and $80 \%$ of group- $B$ ) were housewife. More than half (54\%) of the preeclamptic women were primigravid and $60 \%$ of normal pregnant women were multigravid. Among the preeclamptic subjects 16 (32\%) had mild hypertension $(D B P<110 \mathrm{mmHg})$ and $34(68 \%)$ had severe hypertension (DBP $\geq 110 \mathrm{mmHg}$ ). Out of 50 preeclamptic subjects $45(90 \%)$ had severe proteinuria (+++) and only $5(10 \%)$ had moderate (++) proteinuria. The mean haematocrit value of preeclamptic patients was $34.881 \pm 3.03$ and that of normal pregnant women was $31.94 \pm 1.2$. It was statistically significant ( $P$ value 0.001). The mean haematocrit value of normal pregnant, mild and severe preeclamptic women were $31.94 \pm 1.2,33.31 \pm 2.57$ and $35.62 \pm 2.95$ respectively. It was also statistically significant ( $P$ value 0.001 ).

Conclusion: This study shows that haematocrit value of preeclamptic patients is significantly higher compared to that of the normal pregnant women $(P<0.05)$. There is a strong association of increasead haematocrit and preeclampsia.
\end{abstract}

Key words: Haematocrit, Preeclampsia.

\section{Introduction:}

Preeclampsia/eclampsia is a common complication affecting $2 \%-8 \%$ of pregnancies ${ }^{1}$. WHO estimates that the incidence of preeclampsia is 7 times higher in low and middle income countries than in high income countries and the risk of a woman in low income country dying of preeclampsia/eclampsia is 300 times that of a woman in high income country ${ }^{2,3}$.

In a Baseline survey for assessment of Emergency Obstetric Care services in Bangladesh, $5 \%$ of the total obstetric admission in health facilities were due to preeclampsia and eclampsia ${ }^{4}$.
Preeclampsia-eclampsia is a significant cause of maternal and perinatal mortality and morbidity. In Bangladesh eclampsia contributes $16 \%$ of the maternal mortality on a national basis which is equivalent to about 4500 women in one year ${ }^{5}$.

The "Report of the National High Blood Pressure Education Program Working Group on High Blood Pressure in Pregnancy"6 described the expectant mothers with hypertension were predisposed toward the development of potentially lethal complications, notably abruptio placentae, disseminated intravascular coagulation, cerebral hemorrhage, hepatic failure and acute renal failure.

1. Junior Consultant-Gynae \& Obs, District Sadar Hospital, Feni.

2. Ex-Professor and Head, Dept. of Gynae \& Obs, Dhaka Medical College Hospital, Dhaka.

3. Ex-Professor and Head, Dept. of Gynae \& Obs, Dhaka Medical College Hospital, Dhaka.

4. Associate Professor-Gynae \& Obs, ICMH, Matuail, Dhaka.

5. Junior Consultant-Gynae \& Obs, Shaheed Suhrawardy Medical College Hospital, Dhaka. 
In describing the pathophysiology of preeclampsia it is said as "The Disease of Theories" as the exact course of the disease is not known. It is known that preeclampsia is fundamentally related to poor trophoblast invasion in the myometrium and this results in maternal spiral arteries being hampered in their normal physiological vasodilatation. It is clear that impaired intervillous blood flow results in inadequate perfusion and ischaemia in second half of pregnancy. This probably results in the production of reactive oxygen species ${ }^{7}$.

It is known that the increase in intravascular volume that normally occurs during pregnancy is minimal or completely absent in patients with preeclampsia. The reduced volume is predominantly of plasma and as a result, haemoconcentration result as the disease progresses $^{8}$. Preeclampsia represents a state of haemoconcentratioin and increased haematocrit levels. A fall in repeat haematocrit values may denote clinical improvement ${ }^{9}$.

Mean haematocrit values are slightly but significantly higher at the early stage of hypertension. Plasma volume is significantly reduced and it can account in part for the increased haematocrit ${ }^{10}$.

A higher haematocrit occurred in women of preeclampsia than in normal patients of comparable gestational age. With preeclampsia haematocrit values are invariably above those in normal pregnant women. Normal pregnancy is characterized by a marked expansion in plasma volume ${ }^{11}$.

Plasma volume and haematocrit show a significant correlation. Plasma volume reduction measured indirectly by the elevated haematocrit influences the blood viscosity. Low plasma volume or high haematocrit especially in second trimester are associated with increased frequencies of fetal growth retardation, fetal death, preterm deliveries and preeclampsia $^{12}$.

One important observation was obtained from the study of Saunders et $\mathrm{al}^{13}$ that "Maternal haematocrit in labour is related to fetal cord $\mathrm{pH}$ at delivery". The observed relation between maternal haematocrit and cord $\mathrm{pH}$ possibly reflects the fact that adequate plasma volume expansion is the hallmark of successful pregnancy. Where such change has been suboptimal, the resulting high haematocrit may be therefore merely an indicator of poor quality pregnancy.
Preeclampsia is independently responsible for both the poor outcome and a high haematocrit. The association between high haematocrit and poor outcome remained significant even when hypertension was taken into consideration. Instead, it appears that low haematocrits are associated with little or no risk of fetal growth retardation or preterm delivery, whereas high haematocrit are associated with a significantly increased risk of these complication ${ }^{14}$.

Association between preeclampsia and haematocrit values were determined by different studies in different countries. But this study was done on Bangladeshi women to see the association between preeclampsia and haematocrit values.

\section{Materials and Methods:}

This cross sectional study was conducted in the Department of Obstetrics \& Gynaecology, Dhaka Medical College Hospital (DMCH), Dhaka during the period of January 2012 to December 2013. The study population included patients attending the antenatal clinic and admitted in the department of Obstetrics \& Gynaecology, DMCH. Study population were divided into two groups- Group-A and Group-B. Pregnant women of gestational age between 24 to 40 weeks with preeclampsia were included in the Group-A and the pregnant woman of same gestational age without preeclampsia were included in the Group-B.

A total of 100 subjects - 50 preeclamptic (Group-A) and 50 normal pregnant (Group-B) women were selected for the study. Subjects were selected purposively according to the availability of the patients. Inclusion criteria for Group-A were gestational age between 24 to 40 weeks, blood pressure: diastolic $\geq 90 \mathrm{~mm} \mathrm{Hg}$ and systolic $\geq 140 \mathrm{~mm} \mathrm{Hg}$ and proteinuria (1+or more measured by Dipstick method of two random clean catch specimen of urine at least 4 hours apart) and inclusion criteria for Group-B were gestational age between 24 to 40 weeks, blood pressure: both diastolic and systolic remain within normal limits and having no medical or obstetric complications. Exclusion criteria were patients with diabetes mellitus, renal disease, urinary tract infection, essential hypertension, heart failure, Chronic Obstructive Pulmonary Diseases (COPD) and using diuretics.

The variables included in the study were age, socioeconomic status, parity, gravidity, gestational age, systolic blood pressure, diastolic blood pressure, haematocrit value, haemoglobin concentration and proteinuria.

Structured questionnaire was prepared which includes all the variables of interest. On receipt of the informed 
written consent, blood sample and urine sample were collected from the study subjects. Proteinuria was measured by dipstick method. A second urine sample was collected after 4 hours to detect proteinuria again. Data were collected from the patients on variables of interest using the structured design by interview, observation, clinical examination, haematological investigations and from the history sheet of the patients. Collected data were processed with the help of software SPSS (Statistical Package for Social Sciences) version- 12.0 and analyzed. The test statistics used to analyze the data were descriptive statistics, Chi-square $\left(x^{2}\right)$ Probability Test and t- test. For all analytical tests the level of significance was $p<0.05$. Ethical clearance for the study was taken from the Ethical Committee, Dhaka Medical College \& Hospital.

With all aseptic precaution $1.5 \mathrm{ml}$ of blood was collected from all the subjects using disposable syringe and blood was transferred to test tube containing EDTA, an anticoagulant for haematological analysis. Haematological analysis of blood was done by the Sysmex XS-800i, an automated haematology analyzer in the Department of Haematology, $\mathrm{DMCH}$.

The RBC were analyzed by the RBC detector using the Hydro Dynamic Focusing method. The haematocrit was calculated via the RBC pulse height detection method. Haemoglobin (HGB) is analyzed by the HGB detector based on the SULFOLYSER (SLS) Haemoglobin detection method.

Estimation of urine protein was done by reagent strips (Uric 2V GP, Bayer GMBH Germany).

\section{Results:}

During the study periods total of 100 subjects were studied of which 50 were preeclamptic (Group-A) and 50 were normal pregnant women (Group-B).

There was no difference in age, social class, occupation, gravidity and gestational age between the groups (Table-I).

Among the preeclamptic subjects $16(32 \%)$ had mild hypertension (DBP $<110 \mathrm{mmHg}$ ) and $34(68 \%)$ had severe hypertension (DBP $\geq 110 \mathrm{mmHg}$ ).

Out of 50 preeclamptic subjects $45(90 \%)$ had severe proteinuria (+++) and only $5(10 \%)$ had moderate $(++)$ proteinuria (Table-II).

Haemoglobin concentration of group-A was 11.51 \pm 1.10 (gm\%) and that of group-B was 10.65 \pm 0.63 (gm\%). Haematocrit value of group-A subjects was 34.88 \pm 3.03 (\%) and that of group-B 31. 94 $\pm 1.2(\%)$. The differences of these parameters between the groups were statistically significant $(p<0.05)$ (Table-III).

Table-I

Socio demographic characteristics of the study subjects $(n=100)$.

\begin{tabular}{|c|c|c|c|c|c|}
\hline \multirow[t]{2}{*}{ Characteristics } & \multicolumn{2}{|c|}{ Group-A $(n=50)$} & \multicolumn{2}{|c|}{ Group-B $(n=50)$} & \multirow[t]{2}{*}{$P$ value } \\
\hline & No & $\%$ & No & $\%$ & \\
\hline \multicolumn{6}{|l|}{ Age in years ${ }^{a}$} \\
\hline$<20$ & 7 & 14 & 5 & 10 & 0.885 \\
\hline$>20-30$ & 34 & 68 & 38 & 76 & \\
\hline$>30$ & 9 & 18 & 7 & 14 & \\
\hline Mean $\pm S D$ & \multirow{2}{*}{\multicolumn{2}{|c|}{$26.50 \pm 5.71$}} & \multirow{2}{*}{\multicolumn{2}{|c|}{$26.26 \pm 4.91$}} & \\
\hline Socio-economic status ${ }^{b}$ & & & & & \\
\hline Lower class & 43 & 86 & 35 & 70 & 0.053 \\
\hline Middle class & 7 & 14 & 15 & 30 & \\
\hline \multicolumn{6}{|l|}{ Occupational status ${ }^{c}$} \\
\hline House wife & 37 & 74 & 40 & 80 & 0.476 \\
\hline Service & 13 & 26 & 10 & 20 & \\
\hline \multicolumn{6}{|l|}{ Gravidad $^{d}$} \\
\hline Primi & 27 & 54 & 20 & 40 & 0.161 \\
\hline Multi & 23 & 46 & 30 & 60 & \\
\hline \multicolumn{6}{|l|}{ Gestational age $e^{e}$} \\
\hline$\leq 32$ weeks & 20 & 40 & 15 & 30 & 0.128 \\
\hline 33-36 weeks & 24 & 48 & 21 & 42 & \\
\hline$>36$ weeks & 6 & 12 & 14 & 28 & \\
\hline
\end{tabular}

a,e- Data were analyzed by using Student's t-Test;

b,c,d-Data were analyzed by using Chi-square $\left(c^{2}\right)$ Test. 
Table-II

Severity of preeclampsia of study subjects $(n=50)$

\begin{tabular}{lcc}
\hline Parameters & Number of Patients & Percentage \\
\hline Diastolic Blood Pressure $(\mathrm{DBP})$ & & \\
Mild (DBP $<110)$ & 16 & 32 \\
Severe $(\mathrm{DBP} \geq 110)$ & 34 & 68 \\
Proteinuria & 5 & 10 \\
Moderate & 55 & 90 \\
Severe & & \\
\hline
\end{tabular}

Table-III

Mean distribution of haematological parameters of study subjects $(n=100)$

\begin{tabular}{lccc}
\hline Parameters & $\begin{array}{c}\text { Group-A } \\
(\mathrm{n}=50) \\
\text { Mean } \pm S D\end{array}$ & $\begin{array}{c}\text { Group-B } \\
(\mathrm{n}=50) \\
\text { Mean } \pm S \mathrm{~S}\end{array}$ & P value \\
\hline Haemoglobin $(\mathrm{gm} / \mathrm{dl})$ & $11.51 \pm 1.10$ & $10.65 \pm 0.63$ & 0.001 \\
Haematocrit $(\%)$ & $34.88 \pm 3.03$ & $31.94 \pm 1.2$ & 0.001 \\
\hline
\end{tabular}

\# Data were analyzed using Student's t-Test

\section{Discussion:}

Preeclampsia is a disorder of unknown aetiology. It is a major cause of maternal and perinatal mortality and morbidity worldwide, particularly in developing countries. Most of the preeclampsia occur in nulliparous women ${ }^{15}$.

Soffronoff et al $^{16}$ found marked hypovolaemia in pregnant women with severe preeclampsia and the reduction in plasma volume was particularly marked in association with severe placental failure, while in the reduction in the erythrocyte volume was less pronounced. From their results there is a high erythrocyte concentration in preeclampsia than in normal pregnancy and particularly high erythrocyte concentration in pregnancies with a poor fetal outcome.

In this study, the group-A (preeclamptic patients) and the group-B (normal pregnant women) were almost identical in terms of age. Most of the subjects of both groups were of $3^{\text {rd }}$ decade. Socioeconomic status of most of the study subjects of both the groups were low. Most of the subjects of both the groups were house wife. Regarding obstetric variables like gestational age and gravidity were homogeneously distributed without any significant difference between the groups.

On analysis of the severity of preeclampsia this study revealed that more than two thirds $(68 \%)$ of the preeclamptic women (group-A) had severe preeclampsia (diastolic blood pressure $\geq 110 \mathrm{mmHg}$ ) and remainders (32\%) had mild preeclampsia (diastolic blood pressure $<110 \mathrm{mmHg}$ ). Ninety percent had severe proteinuria (+++ on dipstick test) and remaining $10 \%$ had moderate $(++)$ proteinuria.

The present study demonstrated that the mean haemoglobin concentration of group-A women was $11.51 \mathrm{gm} / \mathrm{dl}$ and that of group-B women was 10.65 $\mathrm{gm} / \mathrm{dl}$, and the mean haematocrit value of group-A women was $34.88 \%$ and that of group-B women was $31.94 \%$. Both these haematological parameters were significantly higher in group-A women than in group-B women ( $p$ value 0.001 ) (Table III). The results of this study are supported by the study done by Heilmann et $\mathrm{al}^{17}$.

This study demonstrated that in preeclamptic women the haematocrit values were above those of the normal pregnant women (Table-III). A consequence of increased haemoconcentration is an increase in the viscosity of the blood and that has been found in preeclampsia ${ }^{18}$. In this respect an important observation was found from the study of Aardenburg et $\mathrm{al}^{19}$ that subnormal plasma volume persisting for at least six month postpartum after a preeclamptic pregnancy identifies women at risk for recurrent disease in their next pregnancy.

Haemoglobin concentration and haematocrit value rises both in mild and severe preeclampsia in comparison to normal pregnant women. Heilmann et $\mathrm{al}^{20}$ shown that haematocrit value of both mild and severe preeclampsia 
were significantly different from that of normal pregnant women. They also found that the lower haematocrit of normal pregnancy is associated with a decreased oxygen capacity but with an increased oxygen delivery. In cases with proteinuric hypertension a haematocrit above normal is associated with reduced systemic oxygen transport rate.

Gifford et al $^{6}$ recommended haemoglobin and haematocrit value estimation along with other laboratory evaluation for the women in whom hypertension develops after midpregnancy as, haemoconcentration supports diagnosis of preeclampsia and is an indicator of severity.

Provided that no anaemia exists, estimation of haemoglobin levels during severe preeclampsia are valuable supplements to other and more sophisticated placental function tests ${ }^{20}$. The present study demonstrated the significant rise of haemoglobin / haematocrit value in preeclamptic women over normal pregnant women however it could not say about pregnancy outcome for which large scale prospective study may be performed.

The mean haematocrit value of normal pregnant, preeclamptic women were $31.94 \pm 1.2,34.88 \pm 3.03$ respectively. On the basis of the results of the study it could be concluded that haematocrit value of preeclamptic patients was significantly higher compared to that of the normal pregnant women $(P<0.05)$. So increased haematocrit value is associated with preeclampsia.

\section{References:}

1. Geographic variation in the incidence of hypertension in pregnancy. World Health Organization International Collaborative Study of Hypertensive Disorders of Pregnancy. Am J Obstet Gynecol 1988; 158(1):80-83.

2. Engender Health. Balancing the Scales: Expanding Treatment for Pregnant Women with Life-threatening Hypertensive conditions in Developing countries. A Report on Barriers and solutions to Treat Pre-eclampsia and Eclampsia. New York: Engender Health; 2007.

3. Dolea C, Ambouzahr C. Global Burden of Hypertensive Disorders of Pregnancy in the year 2000. Global Burden of Diseases 2000. Working Paper. Geneva: World Health Organization; 2003.
4. Yasmin HA et al. Baseline Survey for assessment of Emergency Obstetric Care Services in Bangladesh. Bangladesh Institute of Research for Promotion of Essential \& Reproductive Health and Technologies (BIRPERT). 1995:10.

5. Fauveau V, Konij KA, Chakrabarty J, Chowdhury $A L$. Causes of maternal mortality in rural Bangladesh, Bull WHO. 1988; 66(s):643-651.

6. Gifford RW, August PA, Cunningham G, Green LA, Lindheimer MD, McNelllis D. Report of the National High Blood Pressure Education Program Working Group on High Blood Pressure in Pregnancy. Am J Obstet Gyenecol 2000; 183(1):S1-S21.

7. Shennan A. Hypertensive disorders. In Edmonds K editor. Dewhurst's Text Book of Obstetrics \& Gynaecology, $7^{\text {th }}$ edition. Blackwell Publishing, Oxford. 2007:227-235.

8. Arias F. Practical guide to high risk pregnancy and delivery, $2^{\text {nd }}$ edition. Harcourt Brace \& Company Asia PTE Ltd, Singapore. 1993:186.

9. Ratnam SS, Rao KB, Arulkumaran S. Obstetrics and Gynecology for postgraduates, Vol 1. $2^{\text {nd }}$ Edition. Orient Longman, Hydrabad. 1999:60.

10. Lebel M, Grose JH, Blais R. Increased hematocrit with normal red blood cell mass in early borderline essential hypertension. Clin. Exp. Hypertens A 1989; 11(8):1505-1514.

11. Heilmann L, Siekmann U, Schmid-Schonbein $H$, Ludwig H. Hemoconcentration and Preeclamsia. Arch. Gynecol 1981; 231(1):7-21.

12. Heilmann L, Gerhold S, Tempelhoff G.F.V, Pollow $\mathrm{K}$. The role of intravenous volume expansion in moderate preeclampsia. Clin. Hemorheol 2001; 25:83-89.

13. Saunders NJ St. G, Spiby H, Patel D. Maternal haematocrit in labour is related to fetal cord $\mathrm{p}^{\mathrm{H}}$ at delivery. Br J Obstet Gynaecol 1990; 97:11441147.

14. LU ZM, Goldenbarg RL, Cliver SP, Cutter G, Blankson M. The Relationship Betwen Maternal Hematocrit and Pregnancy Outcome. Obstet Gynecol 1991; 77:90-94.

15. Sibai MB. Prevention of preeclampsia: A big disappointment. Am J Obstet Gynecol 1998; 179(5):1275-1278. 
16. Soffronof EC, Kaufman BM, Connanghton JF. Intravascular volume determinations and fetal outcome in hypertensive diseases of pregnancy. Am J Obstet Gynecol 1977; 127:4-9.

17. Heilmann L, Rath W, Pollow K. Hemorheological changes in women with severe preeclampsia. Clin. Hemorheol. Microcirc 2004; 31:49-58.

18. Sagen $N$, Koller $O$, Haram $K$. Haemoconcentration in severe preeclampsia. $\mathrm{Br}$ J Obstet Gynaecol 1982; 89:802-805.
19. Aardenbug R, Spaanderman MEA, Ekhart TH, van Eijndhoven HW, vander Heijden OWH, Peeters LLH. Low plasma volume following pregnancy complicated by pre-eclampsia predisposes for hypertensive disease in a next pregnancy. Br J Obstet Gynaecol 2003; 110:1001-1006.

20. Heilmann L, Siekmann U. Hemodynamic and hemorheological profile in women with proteinuric hypertension of pregnancy and in pregnant controls. Arch Gynecol Obstet 1989; 246:159-168. 